\title{
Perceptions of the Directors and Principals Regarding Teacher Education Program in Khyber-Pakhtonkhwa, Pakistan
}

\author{
Amjad Reba ${ }^{1}$, Shafqat Parveen ${ }^{1}$, Muhammad Inam Ullah ${ }^{1} \&$ Izaz Ali $^{1}$ \\ ${ }^{1}$ Institute of Education and Research, University of Peshawar, Pakistan \\ Correspondence: Amjad Reba, Institute of Education and Research, University of Peshawar, Pakistan. Tel: \\ 92-91-921-6756/92-332-909-1575. E-mail: rebaamjad5@yahoo.com
}

\author{
Received: November 18, 2012 Accepted: January 16, 2013 Online Published: February 28, 2013 \\ doi:10.5539/ass.v9n3p216 \\ URL: http://dx.doi.org/10.5539/ass.v9n3p216
}

\begin{abstract}
The purpose of this study was to evaluate the teacher education program in Khyber-Pakhtonkhwa to investigate the perceptions of the directors and principals of different programs related to different aspects of teacher education institutes and to suggest recomendations for teacher education institutes in Khyber-Pakhtonkhwa. Interview contained 20 items grouped under seven broad categories was conducted. Ten regional institutes for teacher education (RITEs), five each male and female and five institutes of education and research (IERs) were the sample institutes. Fifteen principals/ directors were the sample size of the study. The results from the interview with directors and principals were documented. The qualitative data reflect broad consensus that access for every learner to modern technology could be made possible. As reflected by the respondents, curriculum must be equipped with the national and international requirements. It is recommended that all vacant posts in teacher training institutes may be filled, to introduce modern assessment techniques, to strengthen teaching practicum and improve research activities in teacher education institutes.
\end{abstract}

Keywords: KPK, Khyber Pakhtonkhwa

\section{Introduction}

\subsection{Introduce the Problem}

Education is to develop the mind and equip the learner to deal with reality. This is a sort of training to think, to understand, to integrate and to prove. The knowledge of the past has to be transmitted to the learner so as to gain knowledge of the present and future. The central task of education is providing facilities to the child. The purpose of education is to teach, to think rationally and to leave a man in condition of continuously asking questions (Teacher mind.com, 2002). According to article A of the constitution, every child has the right to education, so opportunities for education would lead towards the socioeconomic development of the country. The Government has emphasized not only on the quantitative expansion but also on quality of education (Shah, 2003). The Government education policy (1998-2010) and the education sector reforms (ESR) action plan 2002 - 2006 endorsed that quality of education as the key to success. They linked quality of education with teacher training. The world education Forum, Dakar Framework of Action (2000), stated that:

"Improving all aspects of the education and ensuring their excellence of all so that recognized and measurable learning outcomes are achieved by all especially in literacy, and essential life skills". Article 7(vi).

National education policy 1998-2010 pointed out that the teacher education institutes are lacking of facilities, equipment, furniture, learning materials and updated technology, books and other helping aids. The trainers require these facilities for effective teaching learning process. These institutes also need accurate supervision. This policy further emphasized that the teacher education institutes are having financial problems and are not properly equipped to fulfill the needs of a quality teacher training program. National action plan 2002-2006 established National Education Assessment system, the main objectives of this project was to assess performance of teachers and educational institutions by relating it to the learning achievements of students. The action plan expressed the need of those international, national and regional institutes having the expertise in assessment to be linked with the Pakistani institutes for the capacity building.

The Higher education commission (2005) aimed to encourage institutions to enhance the quality of education, promote the prevailing teacher training programs and conduct research for the promotion of education in 
Pakistan. National Action Plan (2002- 2006) focused on institutionalizing the incentives and accountability of the system for teachers to improve their performance. In order to achieve quality education, the teacher training program, particularly, teacher education institutes need to be equipped and improved. Teacher education universally recognizes that the quality of education is dependent upon the quality of teaching. If the teachers are well-trained and highly motivated, learning will be enhanced. Conversely, if the teachers are ill-trained and poorly motivated, learning will be diminished. Acceptance of this linkage often results in emphasis on teacher education. But teacher training is not a cure all for educational ills.

According to the Directory of Teacher Education Institutions in Pakistan (USAID \& UNESCO, 2009), altogether there are 83 institutions (28 in public sector and 55 in private sectors) providing teachers education in KPK. Pakistan Education Statistics 2008-2009 (AEPM, 2009) reports 33 teacher training institutions (27 public sector and 7 private sector) working for teacher education in the province. The Bureau of curriculum was established in 1972. In 1983 the status of the institute was raised to Bureau of curriculum and Education Extension services. In 2001, the status was revised as Directorate of curriculum and Teacher Education (DCTE). One of the primary functions of DCTE is to assist in development and review of curriculum and textbooks from early childhood to grade 12. DCTE manages 20 Regional Institutes for Teacher Education (RITE) and two specialized institutions spread through out KPK. The planning, management, supervision and assessment of RITEs are a regular feature of DCTE's annual scope of work. DCTE is the examining body for Diploma in Education, Certificate in Drawing Master, Junior Diploma in Physical Education, and Certificate in Agro Technical. The conventional PTC and CT courses have been abolished recently and the ADE associate degree in Education is introduced for which RITE affiliated with their respective universities. Originally, Regional institutes for teacher Education (RITE) were established as government colleges of Elementary Teachers (GCET). The institutes underwent a restructuring process and were converted to (RITE) in 2002. The RITE serves as the extension arm of the DCTE reaching out to the teacher at the district level. Their main responsibility is teacher training (Documentation \& Institutional Assessment of DCTE, 2008).

\subsection{Explore Importance of the Problem}

AED (2006) \& Hayes (1987) were are view that there is hue and cry for putting an accountability system in place. There is a distinct lack of public accountability in how education and continued professional development of teachers' and other education professionals are managed. Unfortunately, there is no intention to bring various public and private sector teacher training institutions under the influence of a centralized policy regime. Thus, as pointed out by the teachers, the distinct lack of public accountability in the teacher education system in Khyber-Pakhtunkhwa has led to substandard teacher education programs offered by different institutions in the public as well as in the private sectors.

The National Educational Policy 2009 underscores the need for seeking innovative, cost effective ways to grapple with the demand of quality and accessibility in the context of teacher education. Therefore, expansion of education provision with corresponding emphasis on the need to reduce cost and increase access and enhance quality of teacher education system inevitably requires adopting unconventional approach to teacher education and professional development. It is perhaps due to this lack of policy framework that teacher education programs lack teaching standards. The lack of standard for education in fact creates difficulties in harmonizing school education with teacher education. There is an urgent need to bring the operation of various teacher training institutions in the province and their programs under a viable and a well-defined policy framework enacted and enforced by the provincial government.

To ensure and enhance the quality of education, the HEC has constituted the National Accreditation Council for teacher education (NACTE) 2009 as an autonomous body to accredit all teacher education programs offered in public and private sector institutes, which initiated National Standards for accreditation of teacher education programs. These standards are related to: curriculum, evaluation, physical infrastructure, human resources, finance management and community links.

\subsection{Relevant Scholarship}

Education for All (2003) reported the quality of education is difficult to define; its clear definition is difficult largely due to a large number of stakeholders' alongwith the complexities of the teaching-learning process all of which need to be addressed. Educationists view quality of education as the learning outcomes of learner which are the basic concern of all stakeholders and, as ongoing process, the quality of education can be achieved through an effective teaching learning process. The output in quality could be attained by maintaining the quality of education at all circles of influence.

The ACEID (1995) conference stated that education always needs reforms as highlighted in the recommendation 
on the status of teachers of 1966 . The initial step 30 years later, proved to be very relevant, to catch-up. There is a view they will not, because it shows that these reforms being introduced are not in proper sequence. They need to be addressed properly such as education for durable progress power shifting at the grassroots level; implement reforms in collaboration; improving teacher training to signify the part played by the teacher; adopting certain criteria recognizing that the teacher is an agent of change and coordination among different aspect of education. Reengineering focuses on future goals. It initiates innovations and explores ways, keeping in view the hindrances which mislead the path to reach the desired goals.

Ordonez (1995) suggests that teacher education institutes do not reflect improvement in pedagogy. Now it is obligatory to en sure the quality of education at all levels and to improve the quality of teacher education in teacher training institutes. The study focuses on the three public sector institutes providing teacher training in KPK. RITE (Regional Institute of Teacher Education) and IER (Institute of Education \& Research), providing training at the secondary level, to integrate or create link between these institutes, to restructure teacher education at all three levels. i.e. Elementary teachers (From grade 1-8) and secondary teachers (From grade 9-12). The study also initiates an action plan to design a program for the teachers of Khyber-Pakhtonkhwa.

\subsection{Research Questions}

1) What are the perceptions of the directors and principals regarding different aspects of teacher education programs?

2) What are the recommendations for improvement of teacher education institutes in KPK?

\section{Method}

To generate qualitative data in the study under 07 broad categories, interview schedule contained 20 item was conducted. Interview schedule focused on the different aspects of teacher training institutes in order to evaluate teacher training program in Khyber pukhtonkwa. The researchers visited the selected sites on randomly selected days and filled up the interview schedule which is structured on the following general aspects: Learning aids/technology, Curriculum \& Courses, Admissions, Teaching \& Learning, Evaluation, Research Activities and Teaching practice.

\subsection{Procedure}

As far as qualitative data analysis is concerned, the results from interview schedule with principal respondents were documented while taking notes by the researcher. Randomly sampled interview schedule was used to analyze the qualitative data recorded form principal extended responses to an open-ended question asked in the end of desired interview schedule

\subsection{Population and Sample Size}

All teacher education institutes providing teacher training, teachers and trainees at all level in KPK constituted the population of this study. There are five IER's (Institutes of Education and Research) in KPK. Besides there are 20 RITE's (Regional Institute of Teacher Education) providing teacher trainings at different levels.

The whole province was classified into two broad groups on the basis of male and female (RITE) districts. One district (called stratum) each from the two groups was randomly selected. In this way there were ten sub strata. Directors and Principals of all these institutes were interviewed and the relevant information was collected directly from the respondents. As we have five IERs in KPK so all these institutes were comprised as sample institutes. 15 Principals/ Directors constituted the sample size of the study. The sample selection as discussed above is shown in the form of a flow chart as under: 


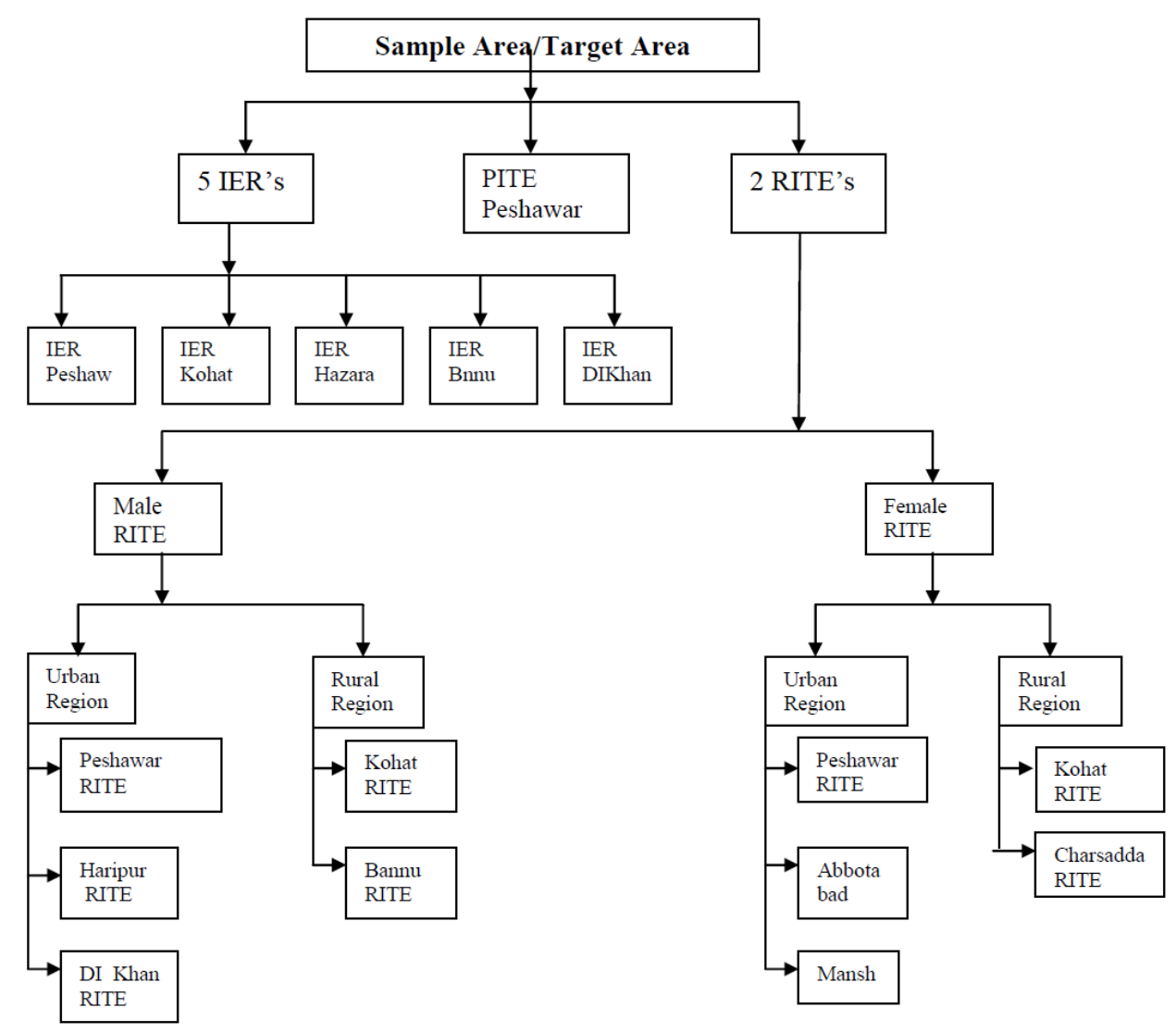

Figure 1.

\subsection{Instrument: Interview}

Interview schedule were conducted to get relevant information from the directors / principals of sample institutes. The Interview schedule aimed at capturing a detailed picture of what is taking place in the teacher training institutes of Khyber-Pakhtunkhwa.

\subsection{Ethical Consideration}

All research studies conducted with humans need to follow an ethical procedure to protect the participants from any moral deflection. As this study involved human subjects, it was required to follow these ethical procedures:

1) Seek informed consent from the participants of the study. The participants were provided detailed information about the study explaining the focus, significance and demands of the study.

2) Participation in the study was declared voluntary; all participants invited for the research had the choice whether or not to participate in the study. They also reserved the right to withdraw from the study at any stage without notifying the researcher about their decision.

3) Confidentiality was maintained; participant's and institution's identity such as name, location, etc. will not be revealed in any form such as report, publication or conference presentations.

\section{Results}

Collection of qualitative data using the interview schedule helped to carry out a multidimensional analysis of teachers' education programs in Khyber-Pakhtunkhwa. This multidimensional analysis drawing on methodological triangulation helps not only to authenticate the results but also to see the subtle and visible connections between various aspects of teachers' education programs. The main findings emerging from the qualitative data are explained in relation to each of the above dimensions of the framework used to guide the study.

\subsection{The Respondents' Principals / Directors Perception about Learning Aids/Technology}

Lack of resources is a big issue in teacher training institute. Particularly, in public sector the procedure is totally 
deficient, which really causes problems and hindrances inthe teaching-learning process. The procedure should be flexible and according to the needs of the institute. The training institutes can develop by providing the facilities. Financial constraints should also be addressed appropriately. Provision for these learning aids will facilitate learning and improve the standards of the institute. Two main areas have been identified where to situate the various perceived characteristics of a learning aids/technology. These include strengths and weaknesses in their institutes.

The data reflect a wide agreement that learning aids and technology cannot be separated from the institutes. Being a teacher, one needs these aids for professional development; students need them for quality education and institutes need them for maintaining standards and identities.

Another group of directors makes similar comments: The institute having access to latest technology can cope up with the situation accordingly and can fulfill the demands of the students and society by and large.

Yet another group of principals argues that the quality of education directly depends upon the quality of aids and technology provided which make an institute distinct from the other institutes. Due to lack of resources and minimum allocation of budget to education, it is almost impossible to equip our learners with modern technology. They recommended computer education as a compulsory subject in all training institutes.

The above perspectives emphasize the need of having proper aids and technology in the institute to equip learners with updated knowledge. It also confirms the objectives of the Provincial Plan of Action for KPK: 2002.

\subsection{The Respondent Principals / Directors Perception about Curriculum}

Curriculum planners, subject specialists, psychologists, philosophers, researchers and statisticians are group of experts needed to update the curricula in order to keep up nationally and internationally. The teacher should be equipped with the necessary pedagogical skills so that he/ she can play a role as an agent of change. Similarly, ITA (2004) argued that alteration in curriculum need to be done in accordance with the requirements and interests of the learner and the teacher needs proper training before implementing the curriculum changes in the classroom context.

CIDA (2005) added that curricula can be modified so that the focus will be on the knowledge and teaching skills of the trainees that teachers can be life long learners. Integration of the subjects is the key for teachers to learn, because this is the most recent approach to teaching and very helpful for the learner.

A group of directors, for example, view the curriculum as:

While designing or developing curricula the students need, interest and demand of the societal expectations should be kept in mind. The curriculum development process should be easy and convenient so that the changing situation can keep up with the explosion of knowledge and can easily be accommodated in the curriculum". It should be a continuous process to meet the call of the time.

Another group of Principals visualizes curriculum as:

We need up-to-date curriculum: courses should be so designed that fulfill the requirements and needs expressed by the teachers. Pre-service and in-service curricula need total revision so that can improve and enhance content knowledge and pedagogical skills of the teacher trainees. Overlapping content in most of the subjects needs proper modification.

According to yet another group of directors/principals, there should be uniformity in the curricula in all teacher training institutes. We need integration of the institutes from higher to elementary levels so that there can be horizontal and vertical alignment in the courses and the trainee should have clear vision. The private sector may be encouraged to follow the same curriculum so that there should be single curriculum for all students.

All the above perspectives and arguments illuminate some of the fundamental characteristics of a curriculum such as producing life long learner. Creating critical thinking and learner diversity may also be included.

\subsection{The Respondent Principals / Directors Perception about Admissions}

It is widely believed that the social status of teachers is deplorably low in Pakistan. This is due largely to the fact that teaching itself is considered to be a low profile profession in the country. This is why it does not attract talented people; instead people with inadequate or mediocre educational backgrounds and who have poor self-images join teaching thus causing erosion to the status of teaching profession (Ali, 2007). Raising the status of the teaching profession needs efforts on multiple fronts, including adopting merit-based recruitment policy, provision of quality education programs and proper criteria for admission in teacher training institutes (Khan 2000; UESCO, 2003; UNESCO, USAID \& Idara-e-Taleem- Aagahi, 2008). To enhance the status of the teaching 
profession, talented and better caliber students, who have aptitude for teaching profession, could be attracted to pre-service teacher education programs. We must recruit teachers at all levels (pre-school, primary/elementary and secondary on the basis of their academic and professional qualifications and aptitude. The prospective teachers who do not qualify for the Provincial Teacher Certification Examination should not be allowed to practice the teaching profession within the public or private school systems. The education commission KPK repot (1985) focused on the candidates and concluded that before joining the department or taking admission to the training classes, candidates shall be required to pass the standardized aptitude and psychological tests, and a written test in the subjects of their fields.

A group of directors/principals presented these views: admission in the teachers training institutes are purely on merit. Merit policy set by the director admissions are properly implemented in the universities and for RITEs policy is set by the government. We never observe violation of merit in our admissions.

A group of directors and principals, for example, agreed to describe an 'admission':

In our society, material well-being is highly recognized; the teaching profession with low incomes is becoming less and less attractive to the younger generation. It is therefore a low profession for the talented students so gifted students or students on the top of the merit are not attracted towards the teaching profession; therefore, merit for admission is very low as compared to other professions.

Another group of directors/principals makes similar comments: Criteria for admission are not inline with the requirements of the profession. That's why teachers are always by chance in the profession which really causes problems at all levels. For quality of education, particularly in the teacher training institutes, aptitude tests should be conducted in order to have teachers by choice in the profession.

It is also supported by education policy 1998-2010. However, none of them discusses admission fee which is a major problem at university level.

\subsection{The Respondent Principals / Directors Perception Regarding Teaching Learning Process}

Teaching learning process needs modification. A teacher-centered approach need to be shifted to learner-centered approach. Effective teaching includes cooperative teaching, activity-based teaching, group discussion, project methods, etc. These are very helpful to activate learners in the class. Different teachers used different methodologies, but varying methods are considered to be very effective inthe teaching and learning process. These methods are likes vehicle which can carry a lot of burden easily.

There appears to be a complete agreement among the directors and principals about a certain set of pedagogical skills, knowledge and attitudes essential to be acquired or displayed by professionally competent teachers. The kind of knowledge of pedagogy and classroom based educational processes the teachers consistently refer to are awareness about different and modern techniques used in teaching of the concerned subject, skills in planning good lessons, setting worthwhile and achievable lesson objectives, using ways, techniques and activities focused on these objectives, assigning purposeful tasks to students individually, (in pairs or in groups), engaging students in practical/experimental work, knowledge of different educational resources, using teaching aids suiting the lesson, using new equipment and technologies such as computer and internet, involving individual students in the teaching and learning process, and using innovative ways to evaluate student learning during and at the end of lessons.

Similarly, another group of directors and principals argues, that the teacher should have deep and broad knowledge about instructional strategies and active learning methods so that he or she can promote effective learning in the classroom.

Yet another director' and principals' group stresses, "Teacher should have the ability to relate the topic with daily life examples and make connections with different experiences students gained outside classroom"

One of the Principal reflects

"I think teachers and students should form a friendly environment in their learning and teaching process. More activities should be there. More A.V. aids should be used. Children should be given more importance and their opinion should be valued. Lessons should be made effective through group discussion".

According to the general opinion of directors and principals, teaching and learning practices we use in the classroom are traditional; we depend solely on transmission of knowledge through lecture; the main thrust of our teaching is on getting students to memorize information, which does not help them understand the basic concepts of their subject; students neither can correctly answer our questions nor fully participate in learning process. 
The teachers' perspectives about essential professional competencies suggest that the expertise of a competent pedagogue needs to combine a wide range of teaching and manipulative skills, deeper understanding of teaching methodologies and approaches and knowledge of the theories underlying these approaches. Mastery in pedagogy can come through genuine engagement with pedagogical practices and constant reflection on these practices.

\subsection{The Respondent Principals / Directors Perception Regarding Evaluation}

A uniform performance appraisal mechanism must be devised at each level and its implementation ensured. The appraisals would be valuable to the recommended information feedback loop. The existing traditional methods of assessment are predominantly based on written examinations. Assessment should not simply cover knowledge but also should focus on deeper understanding of the subject knowledge, organization of knowledge, higher-level cognitive processes and changes in behaviours and disposition. A variety of process-oriented assessment practices, such as learning projects, course assignments, and reflective journals, action research dealing with real problems, seminars/workshops, peer evaluation, and portfolios should be used by educators. Selection among these various methods should be most suited to verifying the learning outcomes set out in the course or module.

The data reflect a wide agreement on the fact by the directors and principals that the teachers, evaluation of class activities of an individual and as a whole class', 'the teachers understanding of the characteristics, uses, advantages and limitations of different types of assessment' and 'the teacher's monitoring his/her own teaching strategies in relation to student success' are the essential competencies to be acquired by teachers in order to be able to use authentic assessment practices with their students. The teachers must be aware of the need for adapting innovative techniques to assess students' learning and use classroom assessment as a tool to trace students' progress on regular bases.

Some directors and principals add' that evaluation should not be considered as students evaluation only, it is the evaluation of teacher, program and of the institute. Both formative and summative evaluations should be used for overall evaluation which results in proper feedback. Another point of view regarding evaluation was' that The existing evaluation are not carried out in accordance with the principles of modern education. The evaluation mostly followed by our teachers, which are based on rote memorization, which is not compatible with the needs of present educational trends. So these methods should be added or replaced by innovative practices. These methods are essential for stimulating inquiry and inquisitive attitude in our trainees.

It is obvious from the above reflections shared by the directors and principals that they are well aware of the weaknesses inherent in traditional evaluation practices. Yet another dimension of an evaluation was focused in quantitative data.

\subsection{The Respondent Principals / Directors Perception Regarding Teaching Practice}

Teaching practice, which provides the most powerful learning opportunity for teachers to learn about professional practice, seemed to be the most neglected area in terms of effective practice of supervision, teaching, learning and assessment. Shared development and understanding of the purposes of practicum facilitates, smooth implementation of the teaching practicum, hence a need to negotiate, develop, document and share the purposes and processes with all stakeholders. There is a need to undertake multiple initiatives with the key Teacher Education Institutions in Pakistan. There is a great need to develop the faculty in innovative teaching, learning and assessment approaches in order to harness and develop the perspective teachers.

The directors and principals unanimously agree on the need for bringing about radical changes in teaching practices in the institutes. They point out various conditions or indicators by which to judge the quality of the total learning environment prevalent in our contexts. Some of the recurring themes emerging from respondents' reflections relate to students' overall learning outcomes, certain critical deficiencies reflected in students' learning such as lacking conceptual understanding, critical thinking and power of self-expression. Improved learning environment in schools and transmission-based instructions adopted by the majority of teachers in the classroom are held responsible for deficiencies in students' learning.

Directors and principals share that, teaching practices we use in the classroom are traditional; we depend solely on transmission of knowledge through lecture; the main thrust of our teaching is on getting students memorized information, which does not help them understand the primary concepts of their subject; students neither can correctly answer our questions nor fully participate in learning process. And trainee teachers are learning the old methods of teaching.

The majority of respondents have provided information that portrays a quite negative picture regarding teaching practices in the institutes. The negative posture of the teaching and learning processes or the classroom environment depicted in these data relate to physical, social and psychological environments of the classroom, 
teachers' personality, motivation, teaching methods, subject matter, and teacher-students relationships. Lesson plans are outdated and both teachers and students have no clear directions regarding marking. There is a clear emphasis on the need for modification in teaching practice and to update lesson plans.

\subsection{The Respondent Principals / Directors Perception Regarding Research Activities}

If laboratory schools cease to exist two major unsolved problems in education remain. One is the ever-widening gap between knowledge generated by educational research and practice in the classroom. The other problem is the critical need for an experimental laboratory to refine or field test theory in an environment uncontaminated by the very necessary restrictions imposed on public schools. There is a dire need to train committed and motivated teachers. Highly motivated and inspiring trainees can conduct research for further improvement and progress. Implementation of research needs research-based administration in order to support and implement the findings of research in the classroom context and field.

A group of directors, for example, view the research as a continuous process in order to improve the teacher education program. Universities role may to identify problems and conduct research to find out solutions for the problems. Research is totally practical and it needs continuous monitoring process. All teacher training institutes need integration through research activities.

Directors and principals add that a teacher should be a good researcher in order to tackle the classroom problems immediately. Classroom management, learner diversity, new approaches to teaching and assessments are the broader areas to conduct research and create conducive learning environment for the learner.

Yet another point of view of the respondents endorsed the fact that we are actually short of research. We are unable to link research with real life situations. At the university level students conduct research but for the partial fulfillment of the degree, having no link with the reality of the situation and even if anybody can use it practically.

It is obvious from the above reflections shared by the directors and principals that they are well aware of the weaknesses inherent in our system with special reference to research. Research activities should be introduced in all the teacher training institutes as the quantitative data reported that there was no research in RITES. Even if there is any research that is also not up to the mark. It is rightly supported by education policy 1998-2010.

\section{Discussion}

The data collected across the four distinct yet interlinked aspects helped carryout out a multidimensional analysis of teacher education programs and their different aspects. The following paragraphs discuss findings formulated within each of these areas to reach conclusions and look through implications of these conclusions for policy and practice.

\subsection{Learning Aids/Technology}

The respondents have expressed their views about learning aids and technology to be provided in teacher education institutes of Khyber-Pukhtunkhwa. A closer look at the data suggests that the learning materials provided in the institutes are directly related to the standards of the institutes and the quality of education provided by them. The directors, and principals, views on the provision of these facilities could be not only benefit learnrs but also they would ultimately lead to the achievement of objectives and fulfill societal needs. The data reflect a broad consensus that access of every learner to modern technology could be made possible keeping in view the importance of computer education being compulsory at all levels. There is always a strong base for the argument about the need for allocation of budgets in education. The UNESCO recommendation is that $4 \%$ of the GDP of the budget must be allocated to education, but since the inception of Pakistan we are not being able to allocate sufficient amounts to education resulting in a big hurdle in our development. The developed countries spend more funds on education and therefore the teachers are equipped with all possible resources. Developing countries have created 200 different low cost no cost materials in order to equip the teachers at the latest methods of how to design theses materials at no cost. It is a common saying that "when there is will, there is a way", so teachers can develop as many helping aids as they need to make the learning process more effective. National Accreditation Council for Teacher Education (2009) focused on facilities that ensure a safe healthy and academic environment.

\subsection{Curriculum and Courses}

It is evident from the directors, and principals, reflections that they are not satisfied with the curriculum development process and they desire change. Especially, student needs and interests and societal demands are keys to be kept in mind while framing curriculum. Our curriculum development process is centralized so they 
demanded decentralization.

As reflected by the respondents, that curriculum must be equipped with national and international requirements so that every learner can get fresh knowledge and pedagogical skills. The curriculum of all teacher training institutes needs proper modification. The quantitative data also reflect that most of the trainees and teachers favored modification in curriculum. As explained by the participants, teacher education curricula desired uniformity at all levels not only between the public sector and private sector also would follow the same curricula. The process of curriculum development in our country is a centralized top down approach. This really creates hurdles in the process of designing a curriculum. As an agricultural country we need to develop curriculum to cater to the needs of the majority of the population which is directly related to agriculture. Rural areas problems are increasing day-by-day and there is urbanization. This can be minimized by developing curriculum in accordance with the needs and demands of the society. Curricula need serious modification at all levels to stop white collar general education which is the main cause of unemployment. Proper technical and vocational education need to be started in order to address the problem of unemployment. Teacher education curricula need modification with the focus on four year programs rather than one year programs. It will strengthen the teacher training program and quality of education. National Standards for Accreditation of Teacher Education Programs (NSATEP) 2009 mention the first standard is curriculum which can be properly designed to attain the national professional standards for teacher, is approved by the competent authority and disseminated to all concerned.

\subsection{Admissions}

The data clearly reflect emphasize the admission criteria that were properly followed by the directors and principals in the teacher training institutes. Any negligence in admission can cause a big problem and violation of merit would certainly deteriorate the quality of education. The quantitative data collected through the survey questionnaires also supported this view. Another major problem pointed by the respondents is that top students on merit did not choose teaching as a profession; therefore, mediocre usually select teaching as profession. The situation is further compounded by the fact that many teachers join teaching by chance and not by choice. So it is obligatory to conduct aptitude tests before admission. Another problem faced by the trainees was the admission fee. The fee structure at the university level is very high and therefore trainees now prefer private institutes for their training. To attract the students towards teaching as a profession, incentives and attractive career opportunities should be provided. It is also mentioned in education policy (1998-2010) but with no implementation. The proper plans, implementation of these recommendations will make this profession acceptable to society. According to the Provincial Education Council KPK, the role of the teacher in all academic fields can hardly be over emphasized. No change whatsoever can take place effectively unless and until our teachers are fully committed to their profession. This makes it imperative to pay great attention to their selection procedure and their pre-service and in-service training. At present, selection for admission in different elementary colleges of education is made on merit-cum-quota basis. Colleges of Education / IERs have their own criteria / procedures of selection and there is no co-ordination between the education departments and the IERs. Teachers, once entered in this profession, can hardly be removed from service irrespective of the fact that they are fit or misfit. There is a shortage of trained teachers especially in the field of science education and female education. According to National Accreditation Council for Teacher Education (2009) there are four issues in teacher education, the first is attracting suitable candidates to teaching profession, Secondly, developing teachers through in-service training. Thirdly, recruiting procedures to select suitable candidates and lastly, retaining the best teachers.

\subsection{Teaching Learning Process}

As stated in the findings, the respondents reported that the teaching-learning process should be in line with the latest pedagogical skills and that varying methodologies would helps learners accordingly. They are also cognizant of the various formal and informal ways and means which are relevant and can be used to address the gaps in their critical professional competencies. The data reflect broad consensus that student needs active participation, so passive listening on the part of learners may be avoided. The teacher should take initiative to use the learning aids properly to activate the learner. It is evident from the directors' and principals' reflections that they are not satisfied with the existing teaching-learning process because it is mostly based on traditional methods which need to be improved. Given limited resources and rapid expansion in the teaching force, the traditional teacher education system in the province, which depends on the provision of centered-based pre-service and sporadic in-service training opportunities, would never be able to reach out to growing number of untrained teachers with quality education programs. This is echoed in the country's recent National Educational Policy 2009. The policy underscores the need for seeking innovative, cost effective ways to grapple 
with the demand of quality and accessibility in the context of teacher education. Therefore, expansion of education provisions with corresponding emphasis on the need to reduce cost and increase access and enhance the quality of teacher education system inevitably requires adopting unconventional approaches to teacher education and professional development. All public and private sector teacher education institutions in the province can be encouraged to develop institutional frameworks for innovative approaches to expanding in-service and pre-service training opportunities for teachers by developing infrastructure they may need to acquire and utilize the huge corpus of knowledge internationally available. According to National Accreditation Council for Teacher Education (2009) stress that teacher education creates conditions in the classroom that ensure and facilitate frequent positive interaction among perspective teachers.

\subsection{Evaluation}

Most of the participants of this study tend to concentrate upon the use of assessment in different ways and they, before assessing the learner, have to know about the nitty gritty of assessment so that the desired goals can be achieved in a proper way. The participants of this study stressed the importance of evaluation and added that evaluation is a very broad term and we have to keep all aspects of evaluation. Some teachers, for example refer it to students only and do not provide proper feedback to the learner so that he/s is able to know his/her strengths and weaknesses. As reflected in the above finding, a significant majority of the teachers is not at all satisfied with the existing evaluation system because it is very much traditional. The student has to reproduce the material he/s has memorized and then get the degree. Evaluation is not for the sake of knowledge but the only aim is to get the degree and certificate.

Therefore, the directors and principals stressed the need to use various methods of assessment in order to facilitate the learner in his/her learning difficulties. A gap between theory and practice needs to be minimized. A semester system can be encouraged to replace annual system. For better results private and public sectors should have uniformity while assessing the learner. Practicum need more attention and due weighting will improve the efficiency of trainees. Practice for the teacher is very obligatory and how to assess this practicum is very important question. Different innovative practices such as the portfolio as an innovative practice can be used to enhance the quality of practical work, and ultimately the quality of teaching and learning will be improved. On the other hand, National Accreditation Council for Teacher Education (2009) is authorized to assess and evaluate the quality of teacher education programs conducted by public and private sector institutions.

\subsection{Teaching Practice}

The extraordinary emphasis on teachers' command over knowledge of subject content reflected in qualitative and quantitative data entails examination of the circumstances that shape directors and principals' opinions or experiences about the role of knowledge of subject matter in teaching practice. Numerous factors are identified responsible for inadequate or substandard levels of teaching practice. As a matter of fact, the practical side of teaching which includes understanding individual students, dealing with issues pertaining to classroom management (e.g., dealing with overcrowded or large classes, teaching in multi-grade situation particularly in schools in rural and remote areas, engaging students) in in-depth learning, student assessment and knowledge of subject matter do not get adequate attention. Also, problem solving, discussion and inquiry-oriented learning, the vital elements of teaching, are not emphasized. The teachers unequivocally stated that prescription of readymade solutions and exposition to alien ideas and theories do not work in their context. Each school's context or classroom situation is different. This shifts the demand to development of teachers' capacity to act as problem solvers and change agents. The teaching skills of teachers and use of different methods of teaching, assessment and teaching practice, multi-grade teaching, identification of learning difficulties of pupils, development and use of teaching learning materials and teaching kits are extremely weak. The training programs' teacher trainers rarely try to develop these skills among the trainees because of lack of their own expertise and they treat the pedagogical parts of the training course purely theoretically. In other words, they only teach but fail to train. The preponderance of faculty members with subject based MAs / MScs (without any qualification in teacher education) further reinforces their tendency to engage in abstract treatment of pedagogical content in the secondary school teacher training programs delivered in Colleges of Education (Seminar on quality education, August 30-31, 1995). Teacher training is a professional discipline but is not recognized as such. As a result, teachers and teacher trainers become interchangeable; even trained teaches teach as they were taught initially from their school days onwards and not as they were taught in their teaching practice. No program or institution exists in the country to train professional teacher trainers except short and largely sterile training programs. If laboratory schools cease to exist, two major unsolved problems in education remain. One is the ever-widening gap between knowledge generated by educational research and practice in the classroom. The other thing is the critical need for an experimental laboratory to refine or field test theory in an environment uncontaminated by 
the very necessary restrictions imposed on public schools. Laboratory schools should serve an extremely important function in the preparation of future teachers; that is, of lifetime students of education. What better way to develop creative, knowledgeable teachers than to provide a stimulating environment that emphasizes the systematic study of teaching and learning educational inquiry that involves both teacher educators and future teachers? National Accreditation Council for Teacher Education (2009) also emphasized on the opportunities provided for the supervision of teaching practice and internship through linkages with the school system.

\subsection{Research Activities}

As stated in the findings, the directors and principals stated that research activities are very important for the development of teacher training institutes. All teacher training institutes need to conduct research to resolve their problems on a priority basis. Research can activate and mobilize activities and close coordination can make them understand their problems. Collective efforts will not only strengthen the institutes but also will be able to bring innovations. The data reflect a broad consensus that a teacher should be a good researcher so he/s is able to tackle classroom problems related to learner diversity, classroom management, varying methodologies and guidance and counseling, etc. Another major problem pointed out by the respondents is that research conducted in these institutes is not applicable in real life. There is a need to link research with practice in order to facilitate learning and school life as a whole. The challenges facing teachers inside and outside classroom are complex i.e. they are multifaceted and intricately interlinked with research activities, and quality of education is directly related to the quality of research. Classroom research will enable the teacher and the taught to improve the efficiency of teacher training institutes. The teacher as an agent of change could conduct research for allowing the change in the classroom context. It will remove the previous errors and pave the way for the smooth running of all the activities accordingly. This would obviously require flexibility and adoption in the curriculum framing and changes in the teacher education programs. National Accreditation Council for Teacher Education (2009) aims to facilitates its educators and trainees to undertake research at the individual and institutional levels, to promote educational process.

\section{Recommendations}

As a result of the information obtained from the data analysis, the following recommendations are made:

\subsection{Improving Infrastructure in Teacher Education Institutes}

Based on the findings of the survey, the provincial government should launch a project to address the material and human resource needs of these institutions. Once these institutions are provided, reasonable budgets should be allocated in each fiscal year to support ongoing activities and encourage development and innovations in leading teacher education institutions. For example, this study recommends that computer and internet facility may be provided to all teacher training institutes in order to enhance quality of education in these institutes.

\subsection{Improving Functions of Teacher Education Institutes}

Teacher education institutions should serve as places where ideas are discussed, educational theories are debated, practice are reflected upon, innovations are tested, knowledge is contested and new knowledge is generated and disseminated to influence policies and practices. Neither of these critical functions is reflected for what teacher education institutions are doing. This study suggests that seminars, training work shops and educational conferences may be conducted on regular basis.

\subsection{To Update Teacher Education Curricula}

Curriculum is one of the core constituents of the system of teacher education. According to our general understanding of curriculum, it subsumes all experiences a trainee teacher undergoes during a pre-service or an in-service training program. The study recommends that teacher education curricula may be modified so that it can accommodate individual differences, achieve the desired objectives and, most importantly, it can link theory with practice.

\subsection{To Introduce Modern Approaches in Teaching}

Learner-centered pedagogies that draw upon activity-based approaches in teaching, learning for achieving the higher quality of knowledge and internalized and empirical knowledge, should be used in teacher education classrooms.

\subsection{To Fill all Vacant Posts in Teacher Training Institutes}

To provide quality education in training institutes, it is obligatory to fill all posts that are lying vacant in order to satisfy the learner in all sorts of all around skills. 


\subsection{To Introduce Modern Assessment Techniques}

The existing traditional methods of assessment, predominantly based on written examinations, need to be fleshed out. A variety of process-oriented assessment practices, such as learning projects, course assignments, reflective journals, action research, assignments, presentations, peer evaluation and portfolios should be used by educators for better outcomes.

\subsection{To Introduce Semester System of Examination}

Assessment should not simply cover knowledge but also focus on deeper understanding of the subject knowledge, organization of knowledge, change in behaviours and disposition. This study recommends a semester system to replace an annual system to eliminate malpractices from the system in teacher training institutes of Khyber-Pakhtonkhwa.

\subsection{To Strengthen Teaching Practicum}

As admitted in this study that practicum removes hindrances of the learner, the teaching practice period should include support and supervision from a mentor and some form of compulsory training and formal evaluation of their teaching skills. This study also suggests that lesson plans should be modified accordingly.

\subsection{Improving Research Activities Teacher Education Institutes}

Research is one of most important but missing elements in the practices of teacher education institutes. This study recommends that all academic and professional study programs should have a strong compulsory component of research with emphasis on various research methods in order to bring improvement in teaching.

Consideration should be given to future studies which may examine the teacher education program in different perspectives.

\section{Acknowledgments}

We have no words to express my deepest sense of gratitude to Almighty Allah, who enabled us to complete this paper and to contribute to the noble field of knowledge. Many thanks are due to many people who guided and encouraged us in the pursuit and production of this study. Our special thanks are due to Dr. Arbab Khan Afridi and Dr. Asrar Khattak for their help during the initial phase of the study. We are deeply indebted to our families for leading us into intellectual pursuits with their magnificent devotion and for the confidence they have given. Heartful thanks are extended to and all the staff of RITE male Peshawar for their valuable suggestions, constant encouragement and guidance in the completion of this article. I must also express my thanks and affectionate feelings for Mr. Naeem Zahid for the support and help during the research work.

We are thankful and acknowledge the efforts and cooperation of directors/ principals and all the respondents of IERs and RITEs for supporting us in data collection. In the end we would like to thank our friends who helped us a lot during the process of research.

\section{References}

Academy for Educational Development. (2006). Performance gap analysis and training needs assessment of teacher training institutions. Pakistan teacher education and professional development. Achievement: Evidence from Pakistan. BRIDGES Research Report Series, March No. 8. Cambridge USA: Harvard.

Academy of Educational Planning and Management. (2009). Pakistan Education Statistics 2008-2009. Retrieved April 22, 2011, from: http://www.moe.gov.pk

CIDA. (2005). The Pakistan Canada Debt-for-Education Conversion: Background and Current Status. Briefing Note.

Department of School \& Literacy KPK. (2006). Education Sector 5-Year Plan. Draft (2nd ed.). Government of KPK.

Docomentation \& Institutional Assessment of DCTE. (1998-2008). Directorate of Curriculum and Teacher Education.

Government of Pakistan. (2004). The development of education: National Report Of Pakistan. Ministry of Education. Islamabad.

Government of Pakistan. (2007). Revised White Paper on Education in Pakistan, Islamabad. Group on education. Islamabad; Planning Commission.

Govt of Pakistan, Ministry of Education. (1970). The National Education Policy. Islamabad, Pakistan. 
Govt of Pakistan, Ministry of Education. (1998-2010). The National Education Policy. Islamabad, Pakistan.

Higher Education Commission, Pakistan. (2005). Pakistan Accreditation Council for Teacher Education Rules.

ITA. (2004). Survey Report on World Teachers Day 2004. Lahore.

Judith, L. Y. (2001-2002). The meaning of Education. Retrieved from http://www.TeacherMind.com

Khan, M. (2000). Teachers' professional development: A way of improving Education in Pakistan. International Studies in Educational Administration, 28(2), 57-67.

Ministry of Education, Govt of Pakistan. (2003). Education for All. Quality of Primary Education in Pakistan. UNESCO Office. Islamabad; Pakistan.

Ministry of Education. (2002). Education Sector Reforms Action Plan 2001-2004.

Ministry of Education. (2002). National Plan of Action on Education for All 2000-2006 Pakistan. Government of Pakistan. Islamabad.

National Accreditation Council for Teacher Education in Pakistan. (2009). National Standards for accreditation of Teacher Education Program.

Ordonez, V. (1999). What Type of World? Paper at ACEID-UNESCO Conference, Bangkok.Reich, Robert. 1992. The Wealth of Nations, Vintage Books, New York.

Shah, M. H. (2000).The Impact of PEP-ILE inputs on Children's Achievement and Teacher's Behaviour. PEPGTZ. Abbott Abad.

UNEESCO. (2008). Status of teacher education in the Asia Pacific region. International Reading Association: Bangkok. Retrieved March 5, 2011, from http://www.unescobkk.org/education/apeid/programme

UNESCO and USAID. (2005). Donor Support to Education. Lesson learned meeting. 23-24 June, 2005, Islamabad, Pakistan.

UNESCO. (2003). Status of Teachers in Pakistan. Islamabad. 